\title{
INFUSÃO UTERINA COM BIGUANIDA POLIMÉRICA SOBRE A COLONIZAÇÃO BACTERIANA DO ÚTERO DE VACAS COM INFECÇÃO PUERPERAL APÓS RETENÇÃO DE ENVOLTÓRIOS FETAIS
}

\section{(Biguanide polymeric infusion in the uterine bacterial contamination of cows with puerperal infection after placental retention)}

\author{
GAMBARINI, M.L.'; CARVALHÊDO, A.S. ${ }^{2}$; OLIVEIRA FILHO, B.D. ${ }^{1}$ MESQUITA, A.J.'; \\ FERRAZ, H.T.; VIU, M.A.O.4; LOPES, D.T.; SEELENT, G.J.N. ${ }^{5}$
}

1Prof. EV/UFG, Campus II, CP 131, Goiânia, Goiás, CEP 74001-970 mlgambarini@hotmail.com; ${ }^{2}$ Mestre em Medicina Veterinária, Médico Veterinário Autônomo; ${ }^{3}$ Aluno de Pós-Graduação em Ciência Animal - UFG; ${ }^{4}$ Prof. EV/UFG, Campus Jataí; ${ }^{5}$ Aluno de graduação de Medicina Vetrinária - UFG.

\begin{abstract}
RESUMO - Com o objetivo de estudar a viabilidade da utilização de biguanida polimérica, no tratamento tópico de infecções puerperais em fêmeas bovinas após o parto prematuro, 20 fêmeas Girolando pertencentes a um sistema de produção leiteira, que apresentaram retenção de envoltórios fetais e conseqüentemente endometrite puerperal, foram distribuídas aleatoriamente em dois grupos. O Grupo I, foi constituído de animais que receberam três infusões uterinas de biguanida polimérica; e o Grupo 2, animais não tratados. Foram realizadas colheitas de conteúdo uterino na primeira, terceira e quinta semanas pós-parto para realização de cultivos bacteriológicos, ou seja, antes da infusão, aos 14 e 28 dias após tratamento medicamentoso. O resultado dos cultivos bacteriológicos nos dois grupos demonstrou que a utilização da biguanida polimérica não reduziu a colonização bacteriana no útero dos animais tratados, em comparação àqueles não tratados.
\end{abstract}

Palavras-chave: Bovinos, Endometrite puerperal, microbiologia, tratamento.

\begin{abstract}
This study was carried out with the aim to verify the utilization viability of polymeric biguanide solutions for the topic treatment of puerperal uterine infections in bovine females after premature parturition. Twenty Girolando cows of a dairy farm, with placenta retention and metritis were randomly distributed in two groups. Group 1, constituted of cows that received three uterine infusions of a polymeric biguanide solution, and Group 2, with animals that were not submitted to any treatment. There were taken uterine content samples at the first, third and fifth post partum weeks for bacteriological cultures, that means, before the first infusion, 14 and 28 days after treatment. The founds of bacteriological cultures in the two groups demonstrated that the solution of polymeric biguanide was not effective to reduce uterine bacteriological colonization in cows with post partum infections.
\end{abstract}

Key-words: bovine, puerperal metritis, microbiology, treatment.

\section{Introdução}

A maximização da eficiência reprodutiva depende da rápida restauração do trato reprodutivo pós-parto. O puerpério da vaca estende-se do parto até a completa involução uterina, quando os ciclos estrais estiverem normais e o comportamento estral restabelecido. Nesta fase a involução uterina é um processo séptico. A eliminação de bactérias presentes nos lóquios ocorre normalmente pela contração uterina, produção de substâncias antibacterianas pelo tecido uterino e fagocitose pelos leucócitos (BORDIN, 2000).

A retenção dos envoltórios fetais e as 
infecções uterinas são os distúrbios pós-parto freqüente observados, e poucas afecções têm recebido tratamentos tão diversificados, constituindo-se em tema 2 extremamente controverso. Nos primeiros 15 dias após o parto, 85 a $93 \%$ dos úteros bovinos podem estar contaminados por diferentes bactérias (HUSSAIN e DANIEL,1992). Aproximadamente em torno do $40^{\circ}$ dia, cerca de $30 \%$ dos úteros estão contaminados, e menos de $9 \%$ apresentam esta característica entre 50 e 70 dias após a parição (OLIVEIRA FILHO,1996).

Populações bacterianas mistas estão presentes no útero, sendo que Arcanobacterium pyogenes, Fusobacterium sp e Bacteróides sp são os microrganismos mais freqüentes em culturas de material uterino durante o período de puerpério (OLSON et al., 1986). As culturas podem revelar ainda, o crescimento de Escherichia coli, Streptococcus $s p$ e Proteus sp. O Clostridium sp coloniza ocasionalmente o útero de vacas, podendo causar endometrite gangrenosa severa (KÜBAR e JALASKAS, 2002). Estas bactérias podem atuar sinergicamente, mas o $A$. pyogenes é o causador que persiste por mais tempo no útero, tornando-se o mais ativo causador de infecções uterinas, junto com microrganismos anaeróbios Gram-negativos (WILLIAMS et al. 2005).

A defesa do útero contra estas infecções é a fagocitose e digestão das bactérias pelos leucócitos, principalmente neutrófilos. Embora a atividade neutrofílica esteja diminuída logo após o parto, em bovinos, a alta capacidade dos placentomas em favorecer a migração celular (quimiotaxia) promove a elevação do número de neutrófilos no útero nos dias subseqüentes ao parto, ativando, de alguma forma, os mecanismos naturais de defesa uterina (ZERBE et al. 2002).

As medidas terapêuticas a serem utilizadas para as infecções uterinas inespecíficas devem ser baseadas, sobretudo, na extensão do processo e, sempre que possível, considerando-se o agente (SHELDON e DOBSON, 2004). Quando o processo infeccioso está presente em forma de endometrite puerperal, causada ou não pela retenção dos envoltórios fetais, o protocolo de tratamento deve ser diferenciado, especialmente para conter a grande invasão e proliferação de microrganismos. Nestes casos não só a fagocitose leucocitária está reduzida ou mesmo ausente, como o número de neutrófilos do útero está bem abaixo, daquele considerado normal, porque a quimiotaxia está comprometida (ZERBE et al., 2002; SHELDON e DOBSON, 2004).

O tratamento sistêmico com soluções antimicrobianas tem a desvantagem de comprometer a qualidade do leite para consumo humano (RADOSTITS et al., 2002), levando o clínico a optar pelo tratamento local, com infusões de solução contendo princípios com qualidades antisépticas. A biguanida polimérica é um biocida de amplo espectro bacteriológico agindo contra Gram-positivos e Gram-negativos, pois como a célula bacteriana tem carga negativa, com quantidade suficiente de biguanida polimérica, a carga superficial da célula bacteriana é neutralizada rapidamente e então, revertida. A rápida atração eletrostática entre a biguanida polimérica catiônica e a célula bacteriana de carga negativa contribui para a alta taxa de mortalidade associada a este produto (BOARDMAN, 1969), que tem sido utilizado como solução sanitizante em procedimentos cirúrgicos (OSTRANDER et al., 2005).

Este estudo foi desenvolvido com o objetivo de testar a utilização deste polímero para reduzir a colonização bacteriana em úteros bovinos contaminados por endometrite puerperal após parto prematuro.

\section{Material e Métodos}

No experimento foram usadas 20 fêmeas bovinas da raça Girolando com idade gestacional acima de 240 dias, selecionadas por palpação retal e sorteadas aleatoriamente para serem submetidas à indução de parto prematuro, visando promover a retenção dos envoltórios fetais e estabelecer um quadro clínico de endometrite puerperal aguda. A indução do parto foi realizada através da aplicação intramuscular de $20 \mathrm{mg}$ de dexametasona associada a $0,5 \mathrm{mg}$ de Cloprostenol.

Após o parto e na ocorrência de retenção dos envoltórios fetais e conseqüentemente 
Infusão uterina com biguanida polimérica sobre a colonização bacteriana do útero de vacas com infecçã...

endometrite, procedia-se ao exame por palpação retal para avaliação do útero e cérvix. A partir do $3^{\circ}$ até $05^{\circ}$ dia pós-parto, iniciou-se a colheita de material uterino e a distribuição aleatória das fêmeas em dois grupos de tratamento, com 10 animais cada: G1 (tratado) recebeu três infusões intra-uterinas com $50 \mathrm{~mL}$ de solução de biguanida polimérica (1:6000), uma a cada 24 horas, sendo a primeira imediatamente após a colheita de material intrauterino (primeira semana pós-parto) e G2 (controle) não recebeu tratamento medicamentoso, mas os animais eram submetidos a exame clinico diário para avaliação do estado geral.

As colheitas de secreção uterina foram realizadas respeitando-se a classificação para a duração da fase de puerpério precoce e tardio, sendo a primeira colheita realizada na semana imediatamente após o parto entre o $3^{\circ}$ e $5^{\circ}$ dia; a segunda colheita na terceira semana entre $017^{\circ}$ e $19^{\circ}$ dia e a terceira colheita na quinta semana pós-parto, entre $31^{\circ}$ e o $33^{\circ}$ dia. Após higienização da região perineal e da vulva, introduzia-se uma pipeta plástica protegida por camisa sanitária através da vagina, atravessando-se o canal cervical até o corpo do útero. O conteúdo era então aspirado para o interior da pipeta plástica com o auxílio de seringa plástica descartável acoplada à pipeta por mangueira de borracha. Imediatamente após a retirada da pipeta, suas extremidades eram fechadas com o auxílio de uma pinça metálica aquecida a fogo e remetido ao laboratório de microbiologia. Sessenta amostras de material uterino foram submetidas ao cultivo e isolamento bacteriológico. Os resultados obtidos foram tratados estatisticamente pelo teste do $c^{2}$, para avaliação dos dados qualitativos.

\section{Resultados e Discussão}

A maioria parte das bactérias isoladas nas amostras de conteúdo uterino foi previamente descrita por SHELDON e DOBSON (2004) e WILLIAMS et al. (2005), com exceção do Actinomyces israelii e Providência sp.

As bactérias anaeróbias facultativas mais freqüentes nas amostras do $\mathrm{G} 1$, foram Eschirichia coli, Staphylococcus coagulase positiva e Enterobacter agglomerans, sendo que após a segunda colheita (correspondendo à terceira semana pós-parto) Escherichia coli, Staphylococcus coagulase positiva e Staphylococcus coagulase negativa foram as mais freqüentemente isoladas. A partir da quinta semana pós-parto apenas Staphylococcus coagulase positiva foi isolado. No G2 as bactérias anaeróbias facultativas isoladas foram Escherichia coli, Staphylococcus coagulase positivo, Staphylococcus coagulase negativo e Enterobacter agglomerans, sendo este último verificado em $10 \%$ dos animais. A partir da segunda e terceira colheita foram isolados Staphylococcus coagulase positivo e Staphylococcus coagulase negativo, mostrando redução do número de isolamentos similar a aquele do G1, embora sem tratamento. Antes do tratamento, $10 \%$ dos animais estavam livres de bactérias anaeróbias facultativas no $\mathrm{G} 1$, e $20 \%$ no G2, dado que coincide com as afirmações de HUSSAIN e DANIEL (1992), evidenciando que o grau de contaminação uterina é grande após o estabelecimento de situações mórbidas no útero, e que esta contaminação pode ser caracteristicamente temporária (SHELDON e DOBSON, 2004; WILLIAMS et al., 2005).

$\mathrm{Na}$ segunda colheita feita nas fêmeas do G1 (14 dias após as infusões), 30\% das amostras de conteúdo uterino não apresentaram crescimento bacteriano anaeróbicos facultativo, enquanto que no restante, Escherichia coli, Staphilococcus coagulase positivo e Staphylococcus coagulase negativo foram encontrados. Já no G2, 60\% das amostras não apresentou crescimento bacteriano anaeróbio facultativo, mas Staphylococcus coagulase positivo e Staphylococcus coagulase negativo foram isolados das amostras positivas. A partir da terceira colheita (28 dias após infusão), $80 \%$ das amostras de conteúdo uterino dos animais do G1 não apresentaram crescimento bacteriano anaeróbio facultativo, sendo que em $20 \%$ isolou-se Staphylococcus coagulase positiva, Escherichia coli e Staphylococcus coagulase negativa. Para o G2, em $70 \%$ das amostras não foi possível isolar microrganismos anaeróbios facultativos, e as amostras positivas mostraram crescimento de Staphylococcus coagulase positivo e Staphylococcus coagulase 
negativo, o que demonstrando rápida capacidade de limpeza dos órgãos afetados, como discutido por SHELDON e DOBSON (2004).

$\mathrm{Na}$ ausência de fatores complicadores, tais como manipulação uterina em condições precárias de higiene, a capacidade do útero em recuperar sua integridade através de seus mecanismos próprios de defesa torna-se maior. As bactérias anaeróbias obrigatórias mais comumente isoladas do conteúdo uterino das fêmeas do G1 foram Bacteroides ovatus (70\%) e Streptococcus sp (30\%). Foi isolado Clostridium beijerinckii/butyricum em $20 \%$ das amostras e Streptococcus intermedius de apenas $10 \%$. Streptococcus sp são microrganismos piogênicos que se proliferam rapidamente quando há condições predisponentes. Situações presentes nas endometrites puerperais e o acúmulo de conteúdo purulento no útero, podem reduzir a ação tópica de determinadas substâncias, não permitindo boa difusão do medicamento, e tampouco sua ação sobre a mucosa (BRETZLAFF, 1987).

Para os animais do $\mathrm{G} 2,100 \%$ das amostras mostraram crescimento de bactérias anaeróbias obrigatórias, sendo Bacteróides ovatus (80\%) e Clostridium beijerinckii/ butyricum (40\%) os mais freqüentes, resultados estes semelhantes aos observado no G1. Na segunda colheita, em $40 \%$ das amostras provenientes dos animais do G2 isolaram-se Bacteróides ovatus e em 30\% Streptococcus sp. Em 10\% foi isolado Clostridium beijerinckii/ butiricum que coloniza ocasionalmente o útero de vacas (HUSSAIN et al.,1990). Essa redução de 20 para $10 \%$ na segunda colheita foi importante, pois a espécie pode causar endometrite gangrenosa severa (KÜBAR e JALASKAS, 2002). Os $A$. pyogenes foram isolados em $30 \%$ das amostras de vacas que na primeira colheita estavam livres dessa bactéria; mas segundo COSTA (1995) este microorganismo pode chegar ao útero via hematógena e não deve ser considerado um contaminante habitual ou comensal do útero bovino. No conteúdo uterino das fêmeas do G2, na segunda colheita, houve redução do número de isolamentos de Bacteróides ovatus (50\%), e nenhuma amostra apresentou crescimento de Clostridium beijerinckii/butyricum. Os Streptococcus sp, que haviam sido isolados anteriormente neste grupo esteve presente no conteúdo uterino de $20 \%$ das fêmeas, fato que pode estar relacionado com a atividade sinérgica de microrganismos (BEKANA et al., 1996), favorecida pela queda temporária de resistência local.

$\mathrm{Na}$ terceira colheita, em 10\% das amostras de vacas do G1 foi possível isolar Bacteróides ovatus e $A$. pyogenes, inclusive na amostra de um animal que na segunda colheita estava livre de bactérias anaeróbias, fato que pode ser explicado pela contaminação hematógena (COSTA, 1995). O isolamento desses dois agentes a partir de cultura única pode representar maior gravidade do processo infeccioso, já que estes podem atuar sinergicamente. O Streptococcus $s p$ foi isolado de $20 \%$ das amostras, sendo que em $10 \%$ o isolamento só ocorreu na terceira colheita, quando $60 \%$ das amostras não mostraram crescimento de bactérias anaeróbias, confirmando os dados de HUSSAIN e DANIEL, (1992), SHELDON e DOBSON (2004). Aproximadamente do $40^{\circ}$ dia, $30 \%$ dos úteros podem estar livres de crescimento bacteriano.

Para os animais do $\mathrm{G} 2 \mathrm{em} 70 \%$ das amostras não foi possível isolar agente anaeróbio obrigatório, sendo que Bacteróides ovatus foi o mais freqüente nas amostras positivas (20\%), seguido pelo Streptococcus sp (10\%), embora estes animais não tenham sido submetidos a tratamento medicamentoso. Estes animais retornaram mais precocemente à ciclicidade, 0 que pode justificar a maior rapidez na limpeza do órgão pela ação estrogênica presente, como preconizado por DRILLICH et al. (2003).

A similaridade de resultados entre os dois grupos experimentais quanto à freqüência de agentes isolados, em especial aos agentes anaeróbios obrigatórios, os quais encontram no útero condições adequadas para seu crescimento, pode ser indicativo de que as propriedades da biguanida polimérica, referente à sua capacidade de neutralizar rapidamente a carga superficial da bactéria (BOARDMAN, 1969) pode ser prejudicada ou até inativada pelo tipo de microrganismo presente. 
Infusão uterina com biguanida polimérica sobre a colonização bacteriana do útero de vacas com infecçã...

\section{Conclusões}

Os resultados obtidos permitiram concluir que a utilização de biguanida polimérica, em infusão uterina e na forma utilizada, apresentou baixa eficácia na redução da colonização bacteriana, como método auxiliar no tratamento de endometrite puerperal, requerendo-se novos estudos para se determinar diluição, volume e/ou freqüência de aplicação mais efetiva.

\section{REFERÊNCIAS}

BEKANA M.; JONSSON, P.; KINDAHL, $H$. Intrauterine bacterial findings and hormonal profiles in post-partum cows with normal puerperium. Acta Veterinaria Scandinavica, Copenhagen, v. 37, n. 3, p. 251-63, 1996.

BOARDMAN, G. Food technology in New Zeland. Rev. ICI Pharmaceuticals, v. 10, p. 421-425, 1969.

BORDIN, E.L. Algumas considerações sobre o "Complexo Metrite-Endometrite-Piometra", patogenia clínica e controle. In: CURSO NOVOS ENFOQUES NA PRODUÇÃO E REPRODUÇÃO DE BOVINOS, 4., Botucatu, 2000. Anais... Botucatu: UNESP, 2000. p. 32-37.

BRETZLAFF, K. Rationale for treatment of endometritis in the dairy cow. Veterinary Clinical North American Food Animal Practice, Philadelphia, v. 3, n. 3, p. 593-607, 1987.

COSTA, E.O. Abortos infecciosos em bovinos. In: CONGRESSO BRASILEIRO DE REPRODUÇÃO ANIMAL, 9., 1995, Belo Horizonte. Anais... Belo Horizonte:Colégio Brasileiro de Reprodução Animal, 1995. p.71-79.

DRILICH, M.; PFÜTZNER, A.; SABIN, H.J.; SABIN, M.; HEUWIESER, W. Comparasion of two protocols for the treatment of retained fetal membranes in dairy cattle. Theriogenology, New York, v. 59, n. 3-4, p. 951-960, 2003.
HUSSAIN, A.M.; DANIEL, R.C.; OBOYLE, D. Postpertum uterine flora following normal and abnormal puerperium in eows. Theriogenology, New York, v.34, p.291-302, 1990.

HUSSAIN, A.M.; DANIEL, R.C. Phagocytosis by uterine fluid and blood neutrophiles and hematological changes in postpartum cows following normal and abnormal parturition. Theriogenology, New York, v. 37, p. 1253-1267, 1992.

KÜBAR, H.; JALASKAS, M. Pathological changes in reproductive organs of cows and heifers culled because infertility. Journal of Veterinary Medicine, Berlin, v. 49, n. 7, p. 365-372, 2002.

OLIVEIRA FILHO, B.D. Involução uterina da vaca. Monografia. Jaboticabal, 25p., 1996.

OLSON, J.; BUTZLAFF, K.; MORTINER, R.; BALL, L. The metritis-pyometra complex. In: CURRENT therapy in theriogenology. 2. ed. Philadelphia: W. B. Saundners, 1986. p. 227-236.

OSTRANDER, R.U.; BOTLE, M.J.; BRAGE, M.E. Efficacy of surgical preparation solutions in foot and ankle surgery. Journal of Joint Surgery America, Boston, v. 87, n. 5, p. 980-985, 2005.

RADOSTITS, O.M.; GAY, C.C.; BLOOD, D.C.; HICHCLIFF, K.W. Clínica Veterinária - Um tratado de doenças dos bovinos, ovinos, suínos, caprinos e eqüinos. 9. ed. Rio de Janeiro: Guanabara Koogan, 2002. 1737 p.

SHELDON, I.M.; DOBSON, H. Postpartum uterine health in cattle. Animal Reproduction Science, Amsterdan, v. 82-83, p. 295-306, July 2004.

WILLIAMS, E.J.; FISCHER, D.P.; PFEIFFER, D.U.; ENGLAND, G.C.W.; NOAKES, D.E.; DOBSON, H.; SHELDON, I.M. Clinical evaluation of postpartum vaginal mucus reflects uterine bacterial infection and immune response in cattle. Theriogenology, New York, v. 63, n. 1, 2005.

ZERBE, H.; OBADNIK, C.; LEIBOLD, W.; SCHUBERTH, H.J. Lochial secretions of Escherichia colior Arcanobacterium pyogenes infected bovine uteri modulate the phenotype and functional capacity of neutrophilic granulocytes. Theriogenology, New York, v. 57, n. 3, p. 1161-1177, 2002.

Recebido para publicação: 23/06/2005 Aprovado: 